BMC

Evolutionary Biology

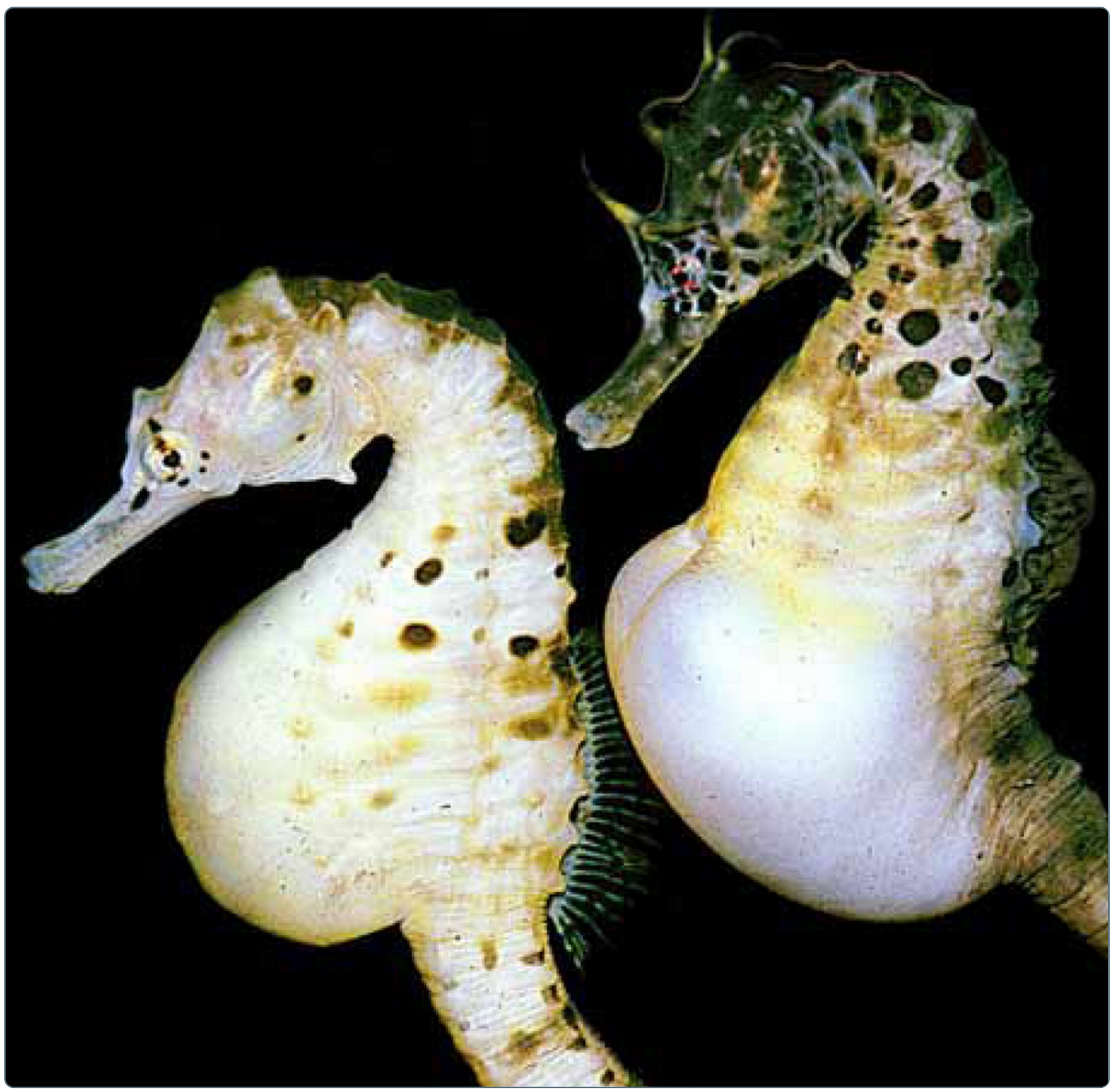

The impact of sex-role reversal on the diversity of the major histocompatibility complex: Insights from the seahorse (Hippocampus abdominalis)

Bahr and Wilson

C Biomed Central

Bahr and Wilson BMC Evolutionary Biology 2011, 11:121

http://www.biomedcentral.com/1471-2148/11/121 (10 May 2011) 


\title{
The impact of sex-role reversal on the diversity of the major histocompatibility complex: Insights from the seahorse (Hippocampus abdominalis)
}

Angela Bahr and Anthony B Wilson

\begin{abstract}
Background: Both natural and sexual selection are thought to influence genetic diversity, but the study of the relative importance of these two factors on ecologically-relevant traits has traditionally focused on species with conventional sex-roles, with male-male competition and female-based mate choice. With its high variability and significance in both immune function and olfactory-mediated mate choice, the major histocompatibility complex $(\mathrm{MHC} / \mathrm{MH})$ is an ideal system in which to evaluate the relative contributions of these two selective forces to genetic diversity. Intrasexual competition and mate choice are both reversed in sex-role reversed species, and sexrelated differences in the detection and use of $\mathrm{MH}$-odor cues are expected to influence the intensity of sexual selection in such species. The seahorse, Hippocampus abdominalis, has an exceptionally highly developed form of male parental care, with female-female competition and male mate choice.

Results: Here, we demonstrate that the sex-role reversed seahorse has a single MH class II beta-chain gene and that the diversity of the seahorse $M H \| \beta$ locus and its pattern of variation are comparable to those detected in species with conventional sex roles. Despite the presence of only a single gene copy, intralocus MHII $\beta$ allelic diversity in this species exceeds that observed in species with multiple copies of this locus. The MHII locus of the seahorse exhibits a novel expression domain in the male brood pouch.

Conclusions: The high variation found at the seahorse MHII gene indicates that sex-role reversed species are capable of maintaining the high MHC diversity typical in most vertebrates.

Whether such species have evolved the capacity to use MH-odor cues during mate choice is presently being investigated using mate choice experiments. If this possibility can be rejected, such systems would offer an exceptional opportunity to study the effects of natural selection in isolation, providing powerful comparative models for understanding the relative importance of selective factors in shaping patterns of genetic variation.
\end{abstract}

\section{Background}

The impact of natural and sexual selection on genetic diversity has been intensively studied in both natural and captive-bred populations [1], but the majority of our current knowledge in this area is derived from species with conventional sex roles, with choosy females and competitive males $[2,3]$. Sex-role reversed species, in which females compete for mating opportunities and males are choosy $[4,5]$, offer exceptional opportunities to investigate central tenets of sexual selection theory

\footnotetext{
* Correspondence: tony.wilson@ieu.uzh.ch

Institute of Evolutionary Biology and Environmental Studies, University of Zurich, Winterthurerstrasse 190, 8057 Zurich, Switzerland
}

and the importance of sexual selection in the maintenance of genetic diversity.

The hypervariable major histocompatibility complex $(\mathrm{MHC} / \mathrm{MH})$ has proven to be a powerful model in which to investigate the importance of natural and sexual selection in shaping genetic diversity [6-8]. The MHC is an essential part of the vertebrate adaptive immune system, and includes a suite of more than 200 genes involved in the destruction of infected cells and the antibody response [9]. There are two major antigenpresenting groups of MHC molecules, class I and class II genes, which differ in their function, structure and pattern of expression [9]. The peptide binding region (PBR) of MHC loci encodes a groove that permits the 
binding of specific antigens, and this region typically exhibits the highest sequence polymorphism within the gene [10].

The investigation of MHC genes in a diversity of vertebrates indicates that these loci are more diverse than any other gene family [9]. Natural selection on MHC is thought to be driven primarily by pathogens, leading to balancing selection that acts on the PBR of MHC genes [11]. Balancing selection operates through either negative frequency-dependent selection, in which the relative fitness of individual alleles is influenced by their frequency (reviewed in [6]), or via heterozygote advantage. The advantage of MHC heterozygosity lies in the potential increase of the number of different parasite-derived antigens that can be detected by a MHC-heterozygous individual's immune system [12]. MHC diversity can be further enhanced by selection on linked genes, due to genetic hitchhiking $[13,14]$. In addition to the importance of MHC genes as an integral part of the adaptive immune system, MHC-mediated odor cues have been shown to be important in mate choice, kin recognition and inbreeding avoidance [15-19]. Disassortative mating is widely believed to promote MHC diversity and to increase the proportion of heterozygote individuals in natural populations $[15,20,21]$. Sexual selection can thus directly contribute to $\mathrm{MHC}$ allelic diversity via disassortative mate choice [12].

Despite consistently high levels of variation, there are major differences in the genomic organization of MHC genes in different vertebrate groups. While these loci are physically linked in mammals, class I and II genes are unlinked in bony fishes (class Actinopterygii) $[22,23]$. Due to the lack of linkage of MHC genes in actinopterygians, Stet et al. [23] have suggested that major histocompatibility genes in these species are most accurately termed $\mathrm{MH}$ loci. The unlinked nature of $\mathrm{MH}$ genes may provide increased evolutionary flexibility and contribute to enhanced $\mathrm{MH}$ diversity in this group. $\mathrm{MH}$ gene diversity is highly variable in teleost fishes, and while some species have a single classical $\mathrm{MH}$ class II beta-chain gene (MHII $\beta$ ) (e.g. salmonids $[24,25])$, most species have multiple copies of this locus (e.g. sticklebacks: 4-6 copies [26], perch: $>8$ copies [27], cichlids: $>10$ copies [28]). This variation may be due, at least in part, to ancestral chromosome or genome duplications [29].

While previous studies on teleosts have shown that both natural and sexual selection structure $\mathrm{MH}$ allelic diversity in species with conventional female-based mate choice [16,30,31], no study to date has investigated $\mathrm{MH}$ variation in sex-role reversed species in which mating decisions are made by the male. Males and females often differ in their ability to detect odor cues $[32,33]$, and sex differences in the production, processing and use of $\mathrm{MH}$-mediated signals are expected to influence the relative efficiency of sexual selection in sex-role reversed and conventionally-mating species, potentially reducing the level of $\mathrm{MH}$ variation in species with reversed sex-roles.

The teleost family Syngnathidae (seahorses and pipefish) is a well-suited model system to study questions concerning the relationship between sex roles and $\mathrm{MH}$ diversity. Both conventional and sex-role reversed species exist in the family and sex-role reversal has evolved several times independently in this group [34]. Studies of wild populations of the potbellied seahorse, Hippocampus abdominalis, have found evidence of femalefemale competition and male mate choice, suggesting that natural populations of this species are sex-role reversed [35].

Here, we characterize $\mathrm{MH}$-variation in wild-caught and captive-bred individuals of sex-role reversed populations of the potbellied seahorse, a species with a highly developed form of male parental care. Genome sequencing and transcriptome screening confirm the existence of a single, highly variable copy of the MHII $\beta$ locus in this species, with a pattern of variation identical to that detected in species with conventional sex roles. This pattern of genetic variation has been influenced by a combination of intralocus recombination and positive selection on sites believed to be important for peptide binding. MHII $\beta$ is expressed in brood pouch tissues of male seahorses, suggesting that these molecules may be functionally active during male pregnancy. Our results indicate that sex-role reversed taxa such as the seahorse are capable of maintaining the high MHC diversity typical of vertebrate species with conventional sex roles.

\section{Results}

The seahorse, Hippocampus abdominalis, has a single MHII $\beta$ locus

Full-length gDNA sequencing of the seahorse MHII locus from a single non-pregnant male identified 2 alleles, closely related to other teleost MHII $\beta$ sequences (Blastn: Hippocampus kuda: e-value $=0.0$, Hippocampus sp.: $\mathrm{e}-\mathrm{value}=2 \mathrm{e}-100$, Monopterus albus: $\mathrm{e}-\mathrm{value}=2 \mathrm{e}-$ 35, Archoplites interruptus: e-value $=1 \mathrm{e}-33$, Tetraodon nigroviridis: e-value $=1 \mathrm{e}-33$ ). The structure of MHII $\beta$ in the seahorse is similar to that in other vertebrates, with 6 exons separated by 5 introns of varying length (Figure 1 ). The total intron length of the 2 full-length alleles differs, resulting in full gene sequences of $3508 \mathrm{bp}$ and $3523 \mathrm{bp}$, respectively. Intron length variability is concentrated in 3 single-bp repetitive regions $\left(A_{n}, C_{n}\right.$ and $\left.T_{n}\right)$ located in introns 2 and 4 (Figure 1).

Complete MHII $\beta$ exon 2 sequences were obtained for 96 captive-bred and 5 wild-caught individuals. Irrespective of the primer combination used, a maximum of two 


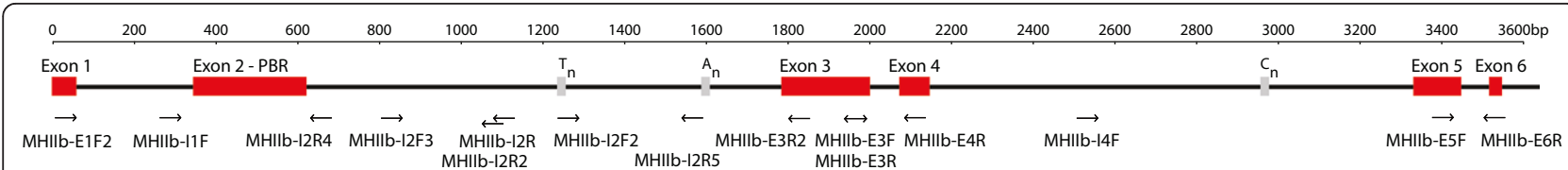

Figure 1 Seahorse MHII $\beta$ gene map. The locations of exons, repetitive regions $\left(A_{n}, C_{n}\right.$ and $\left.T_{n}\right)$ and primers used for genome walking and sequencing (see table 3) are indicated. The peptide binding region (PBR) of MHII $\beta$ is located in exon 2 . The full gene sequence has been submitted to GenBank (Accession \#: HQ902181 and HQ902182).

alleles were found in all 101 individuals, indicating the existence of a single MHII $\beta$ locus in this species. The comparison of parent-offspring $\mathrm{MH}$ profiles in 5 families of seahorses confirmed the Mendelian inheritance of the seahorse MHII $\beta$ locus (Table 1). A 454-cDNA-library of the potbellied seahorse yielded 36 MHII $\beta$ sequences (23 from pregnant pouch tissue (normalized/unnormalized: 18/5), 5 from non-pregnant pouch tissue (2/3), and 8 from normalized reference tissues) which could be assembled into a single contig identical to the MHII $\beta$ genomic DNA sequence. cDNA sequencing indicated that the MHII $\beta$ gene of the seahorse is expressed in muscle, liver and brood pouch tissue.

\section{Sequence polymorphism in the PBR}

Sequencing of the highly-variable peptide binding region of the seahorse MHII $\beta$ locus identified a total of $17 \mathrm{H}$. abdominalis MHII $\beta 1$-domain alleles in 101 individuals (Figure 2). 86\% of individuals were heterozygous for MHII $\beta$ (87 of 101), while $14 \%$ were homozygous, consistent with Hardy-Weinberg expectations (HWE Exact Test: $\mathrm{p}=0.08)$. An analysis of allelic assortment detected 4 allele combinations more frequently than expected by chance (Figure 3; Hiab-DAB-E2*03/*03 $\mathrm{p}=$
$0.020, * 04 / * 05 \mathrm{p}=0.040, * 05 / * 13 \mathrm{p}=0.029, * 07 / * 08 \mathrm{p}=$ 0.001 ), but none of these values remained significant after correcting for multiple comparisons (Sequential Bonferroni correction). The 17 alleles include 25 polymorphic nucleotide sites and a total of 17 amino acid differences (Figure 4). Each of the 17 alleles differs by at least one amino acid substitution (Figure 4,5). All alleles detected in wild individuals (Hiab-DAB-E2*01, $04,05,09,13,16$ and 17) were also detected in the captive-bred population. The nucleotide diversity $\pi$ of the seahorse MHII $\beta 1$-domain is 0.034 . The dataset used for subsequent analyses contains 270 bp of exon 2 (total length: $273 \mathrm{bp}$ ), after omitting exon-spanning codons at the $5^{\prime}$ and $3^{\prime}$ ends of the exon (2 bp and $1 \mathrm{bp}$, respectively).

\section{A strong signal of positive selection}

Only 2 of the 25 nucleotide substitutions detected in exon 2 of the seahorse are synonymous, leading to a $\mathrm{dN} / \mathrm{dS}$ ratio of $3.7(\mathrm{dN}=0.041, \mathrm{dS}=0.011$, Table 2$)$. A strong signal of positive selection was detected in this region ( $Z$-Test $p=0.02$ ), and 11 of the 17 variable amino acid sites are inferred to be under positive selection ( $\mathrm{p}<0.05$, Figure 4) (seahorse sites $4,6,8,17,43$,

Table 1 Mendelian inheritance of MHII $\beta$ in the seahorse

\begin{tabular}{|c|c|c|c|c|c|c|c|c|c|c|c|c|c|c|c|c|c|c|c|c|}
\hline \multirow[b]{2}{*}{ Individual } & \multicolumn{4}{|c|}{ Family A } & \multicolumn{4}{|c|}{ Family B } & \multicolumn{4}{|c|}{ Family C } & \multicolumn{4}{|c|}{ Family D } & \multicolumn{4}{|c|}{ Family E } \\
\hline & A1 & A2 & A3 & A4 & A1 & A2 & A3 & A4 & A1 & A2 & A3 & A4 & A1 & A2 & A3 & A4 & A1 & A2 & A3 & A4 \\
\hline Father & 3 & 4 & & & 2 & 6 & & & 5 & 13 & & & 4 & 9 & & & 2 & 6 & & \\
\hline Mother & & & 4 & 15 & & & 1 & 8 & & & 2 & 8 & & & 6 & 16 & & & 1 & 11 \\
\hline Juvenile 1 & & 4 & 4 & & & 6 & 1 & & & 13 & 2 & & 4 & & 6 & & & 6 & & 11 \\
\hline Juvenile 2 & 3 & & & 15 & & 6 & & 8 & 5 & & 2 & & 4 & & & 16 & 2 & & & 11 \\
\hline Juvenile 3 & & 4 & & 15 & & 6 & 1 & & 5 & & 2 & & & 9 & & 16 & & 6 & 1 & \\
\hline Juvenile 4 & & 4 & & 15 & & 6 & 1 & & & 13 & & 8 & 4 & & 6 & & 2 & & & 11 \\
\hline Juvenile 5 & 3 & & & 15 & & 6 & & 8 & 5 & & & 8 & & 9 & & 16 & & 6 & 1 & \\
\hline Juvenile 6 & 3 & & & 15 & 2 & & 1 & & & 13 & & 8 & & 9 & 6 & & 2 & & 1 & \\
\hline Juvenile 7 & 3 & & 4 & & & 6 & & 8 & & 13 & & 8 & & 9 & 6 & & 2 & & 1 & \\
\hline Juvenile 8 & & 4 & 4 & & & 6 & & 8 & & 13 & & 8 & 4 & & & 16 & 2 & & & 11 \\
\hline Juvenile 9 & 3 & & & 15 & 2 & & 1 & & 5 & & & 8 & & & & & & & & \\
\hline Juvenile 10 & 3 & & & 15 & & & & & & & & & & & & & & & & \\
\hline Juvenile 11 & 3 & & 4 & & & & & & & & & & & & & & & & & \\
\hline Juvenile 12 & 3 & & & 15 & & & & & & & & & & & & & & & & \\
\hline Juvenile 13 & & 4 & & 15 & & & & & & & & & & & & & & & & \\
\hline
\end{tabular}

Combinations of MHII $\beta$ alleles (A1-4) in parents and F1 offspring of 5 families of seahorses (A-E). See Figure 2 for allelic sequences. 


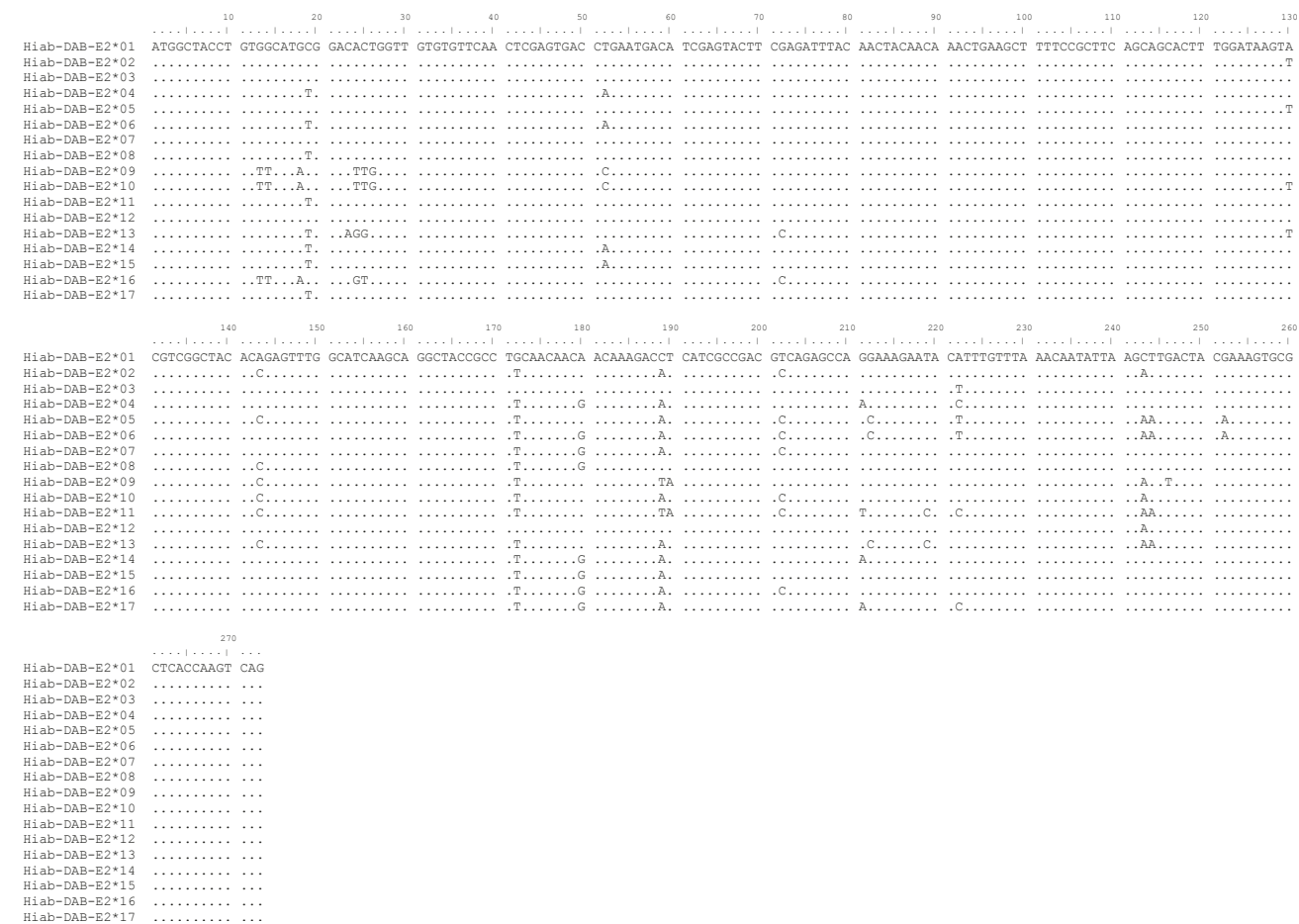

Figure 2 Nucleotide alignment of exon 2. $17 \mathrm{MH} \| \mathrm{\beta}$ exon 2 sequences were obtained in $101 \mathrm{H}$. abdominalis specimens. Dots indicate identity to the first sequence. Synonymous substitutions are shaded in grey. Exon 2 sequences have been submitted to GenBank (Accession \#: HQ902164 - HQ902180).

$60,63,67,70,74$ and 81 ). A model incorporating positive selection fits the exon 2 dataset significantly better than a neutral model of evolution (M8 vs. M7, LRT = 46.744, $\mathrm{df}=2, \mathrm{p}<0.01$ ). Non-peptide binding sites in exon 2 show considerably less non-synonymous variation than do PBS (non-PBS $\mathrm{dN}=0.018$, PBS $\mathrm{dN}=$ $0.128)$ and exhibit no evidence of positive selection $(\mathrm{dN} /$ $\mathrm{d} S=1.5$; Z-Test $\mathrm{p}=0.34$; Table 2).

\section{Detection of recombination}

An allele network based on non-synonymous substitutions was reconstructed to visualize relationships among the 17 unique MHII $\beta$ alleles. The network shows no clear spatial structure, consistent with the pattern expected for a single locus (Figure $5 \mathrm{a}$ ). The reticulative loop in the network suggests the presence of recombinant variants in the dataset, a hypothesis supported by

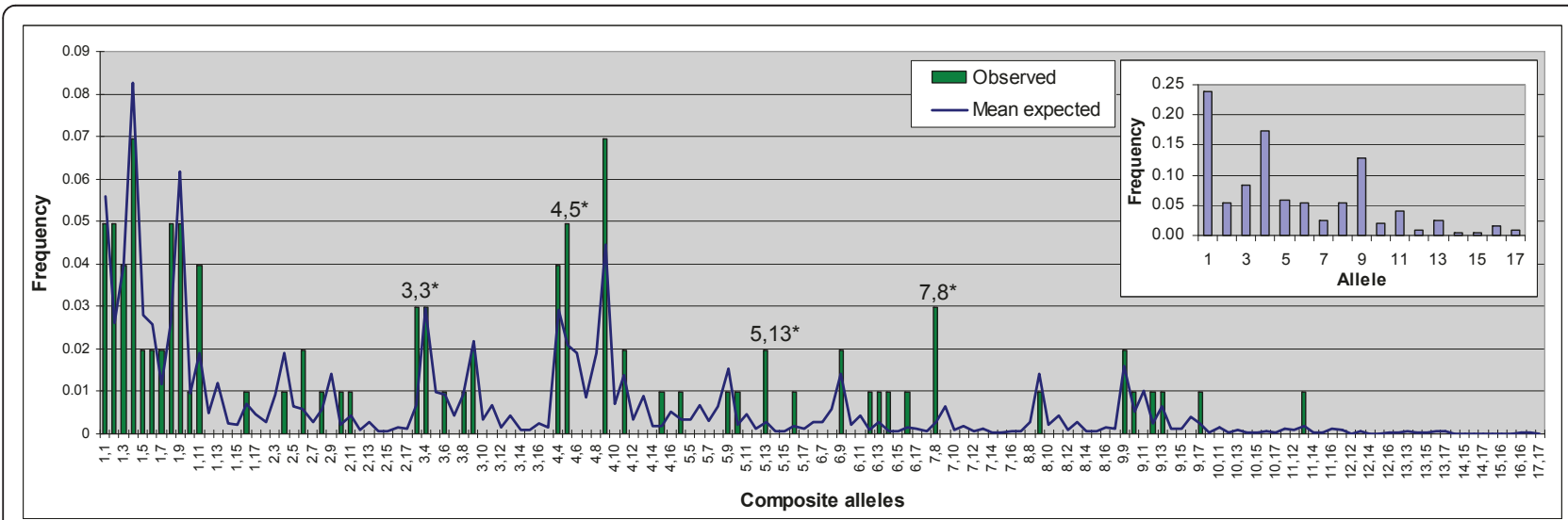

Figure 3 Observed and expected allelic combinations. Bars represent allelic associations observed in 101 H. abdominalis individuals. The mean expected frequencies of allelic combinations were simulated based on empirical allele frequencies (see figure inset). Asterisks indicate significant deviations $(p<0.05)$ from the mean expectation $(N=10,000$ permutations). None of these outliers remain significant after a sequential Bonferroni correction for multiple comparisons. 


\begin{tabular}{|c|c|c|c|c|c|c|c|c|c|}
\hline & 10 & 20 & 30 & 40 & 50 & 60 & 70 & 80 & \\
\hline $\mathrm{Hiab}-\mathrm{DAB}-\mathrm{E} 2 * 01$ & GYLWHADTGC & VF-NSSDLNDI & EYFEIYNYNK & LKLFRFSSTL & DKYVGYTEFG & IKQATACNNN & KDLIADVRAR & KEYICLNNIK & LDYESALTKS \\
\hline $\mathrm{Hiab}-\mathrm{DAB}-\mathrm{E} 2 * 02$ & $\ldots \ldots \ldots$ & $\ldots-\ldots \ldots \ldots$ & $\ldots \ldots \ldots$ & $\ldots \ldots \ldots$ & $\ldots F \ldots \ldots$ & $\ldots \ldots F \ldots$ & .I..... & $\ldots \ldots \ldots$ & I. $\ldots \ldots \ldots$ \\
\hline $\mathrm{Hiab}-\mathrm{DAB}-\mathrm{E} 2$ * 03 & $\ldots \ldots \ldots$ & $\ldots-\ldots \ldots$ & $\ldots \ldots \ldots$ & $\ldots \ldots \ldots$ & $\ldots \ldots \ldots$ & $\ldots \ldots \ldots$ & $\ldots \ldots \ldots$ & $\ldots F$. & $\ldots \ldots \ldots$ \\
\hline $\mathrm{Hiab}-\mathrm{DAB}-\mathrm{E} 2 * 04$ & $\ldots$...... & $\ldots-\ldots Q, \ldots$ & $\ldots \ldots \ldots$ & $\ldots \ldots \ldots$ & $\ldots \ldots \ldots$ & $\ldots \ldots F \ldots D$ & $\ldots I \ldots \ldots K$ & $\ldots \mathrm{L}$. & \\
\hline $\mathrm{Hiab}-\mathrm{DAB}-\mathrm{E} 2 * 05$ & $\ldots \ldots \ldots$ & $\ldots-\ldots \ldots$ & $\ldots \ldots \ldots$ & $\ldots \ldots \ldots$ & $\ldots F \ldots \ldots$ & $\ldots \ldots F \ldots$ & .I...A.S & $\ldots F$. & N..K. \\
\hline $\mathrm{Hiab}-\mathrm{DAB}-\mathrm{E} 2 * 06$ & $\ldots$. v . . & $\ldots-\ldots Q$ & $\ldots \ldots \ldots$ & $\ldots \ldots \ldots$ & $\ldots \ldots \ldots$ & $\ldots \ldots F \ldots D$ & .I...A.S & $\ldots F$. & N..K... \\
\hline $\mathrm{Hiab}-\mathrm{DAB}-\mathrm{E} 2 * 07$ & & $\ldots-$ & & & & ...FF.D & .I..... & & \\
\hline $\mathrm{Hiab}-\mathrm{DAB}-\mathrm{E} 2 * 08$ & $\ldots$. v.... & $\ldots-$. & & $\ldots$ & $\ldots \ldots$ & ...FF.D & & $\ldots$ & \\
\hline $\mathrm{Hiab}-\mathrm{DAB}-\mathrm{E} 2 * 09$ & ..F.T.L. & $\ldots-\ldots P$. & & & & $\ldots \ldots F \ldots$ & ..Y. & & IY.. \\
\hline $\mathrm{Hiab}-\mathrm{DAB}-\mathrm{E} 2 * 10$ & \#F.T.L. & $\ldots-\ldots P$ & & & .F. & $\ldots \ldots F \ldots$ & $\ldots$ I. .A. . & & \\
\hline $\mathrm{Hiab}-\mathrm{DAB}-\mathrm{E} 2 * 11$ & $\ldots$...... & $\ldots-\ldots \ldots$ & $\ldots \ldots \ldots \ldots$ & $\ldots \ldots \ldots$ & $\ldots \ldots \ldots$ & $\ldots \ldots F \ldots$ & .Y...A.M & $\ldots \mathrm{HL} \ldots \ldots$ & \\
\hline$-\mathrm{DAB}-\mathrm{E} 2 * 13$ & $\ldots$. . VEG . & $\ldots-$ & $\ldots Q \ldots$ & & $\ldots F \ldots$ & $\ldots \ldots F \ldots$ & $\ldots I \ldots \ldots S$ & . H. . & N..... \\
\hline $\mathrm{Hiab}-\mathrm{DAB}-\mathrm{E} 2 * 14$ & $\ldots$...... & $\ldots-\ldots Q \ldots$ & $\ldots \ldots \ldots$ & $\ldots \ldots \ldots$ & $\ldots \ldots \ldots$ & $\ldots \ldots F \ldots D$ & $\ldots I \ldots \ldots K$ & $\ldots \ldots \ldots$ & $\ldots \ldots \ldots$ \\
\hline Hia & $\ldots$. v. . . & - & & & & $\ldots \ldots F \ldots D$ & $\ldots I \ldots \ldots$ & & \\
\hline $\mathrm{Hia}$ & .F.T.V. & $\ldots-$ & $\ldots Q$ & & & ...F.D & .I. & $\ldots$ & \\
\hline$b-D A B-E 2 * 17$ & $\ldots$...... & & & & & ...FF.D & $\ldots I \ldots \ldots K$ & ..L. & \\
\hline Gaac|AY713945 & . FMMFVTDE. & . - .TE.K. & .FIRSSYF. . & KEDT. & G.F.F. Q . & V.I.ANW. KD & ASFLSAMK. $Q$ & $\ldots$ VY . . HVP & VY.TA. \\
\hline \begin{tabular}{l|l} 
Gaac & AY713
\end{tabular} & . FMEFRTFR. & ...TE.K. & FF. . & .E.T....SV & G.F.F..Y. & VRN.EYW... & SAMK. $Q$ & . VY . . . HVP & VY.SN. . \\
\hline \begin{tabular}{l|l} 
Paol & $\mathrm{AB} 1$ \\
\end{tabular} & . FRYYVVNS. & E. - . K. . & . FT & .EYI. & G.F...H. & ERW...G & $\mathrm{S}-. \mathrm{GE}$ & $\ldots$ RY ...VVG & V.V. \\
\hline \begin{tabular}{l|l} 
Paol & $A B 126923$
\end{tabular} & .F. HYMVDS. & E. $-\ldots K \ldots$ & . . IYSHY ... & .EYI ....SV & G.F...V. & ..N.ERL..G & PEV.NR- . . - & .PY..T. .N & V $\cdots \cdots$ \\
\hline \begin{tabular}{l|l} 
Paol & AY84
\end{tabular} & .F.HYTV.D. & E. - ..K... & $\ldots T C$ & ..SV & & .N.ERW..G & $S R-. G E$ & ..SY.FH.VG & \\
\hline Stvi AY1 & ...EY.LDR & $\ldots \ldots \ldots$ & $\ldots$ IY & IEDV.... & G. . & L.Y.ENW. .D & PSVL.QR. .Q & .TY.KY.VD & IR \\
\hline \begin{tabular}{l|l} 
Pore & $\mathrm{Z} 54077$
\end{tabular} & . FREF . VDR. & ..S.PE.K. & QFIRS.C... & .EFI.D.N. & .L. & V.N.ERW.KD & TS . . AMK. Q & R.TY...VVG & QN..D. \\
\hline Orla & .FIHYILNR. & L. - . KK. & NIYS.Y. . & EEFL . . . SS & G.F. . I. & V.T.ELA..D & PEKMSRR . . E & .TF.KP.D & N. STI... \\
\hline Суca CAA64709 & . . YEYTMYE. & .Y-ST. .YS.M & V.LVSLSF.Q & VVDVQCN.SA & V.C....E. & V.Y.ENF.KD & PSVLQ.LKTS & VDTY.RS.AQ & . ADS.VRD. A \\
\hline Teni CAF94 & AFEHYGLRR. & D. -T.AEPK.M & . . SLSVY . . & HLMA. . . . SV & G.F. . DKY. & QY. .DYW..Q & SSFLEAM.SS & . QRL.QH . . P & .W.SHI.S. . \\
\hline Taru Ensembl & .FQSYRVDR. & D. -.T.K. . & .. SRSHY. . & .MYV..R.SV & G.FE...KD. & LI . . DYW. . I & SSYLEQM.DE & .RY.EP . . & VW.SNI.S. \\
\hline Sasa AJ43 & . . FEQVVRQ. & RY-S.K. .QG. & .FIDS.VF. . & AEYV . .N. .V & G....L. & V.N.E.W.KG & P-EL. VELGE & L.RF. KH. AA & IY.SAI.D.T \\
\hline \begin{tabular}{l|l} 
Dare & AAA5 0
\end{tabular} & . . YQYTTMLE. & IY-ST..YS.M & VLL.SGSF. . & VVDVQYN..V & G.... & VIF. RNF.K. & QAYLQQRK.E & V.SF.RH.AQ & ISDSAVRDA- \\
\hline Hosa M1116 & DTRPRF. . QLKFE . & H.F.G--TERV & RLL.RCI . Q & EESV..D.DV & GE.RAVE.L. & RPD.EYW.SQ & ...LEQK.GQ & VDNY.RH.YG & VGESFTVQRR \\
\hline & 10 & 20 & 30 & 40 & 50 & 60 & & 80 & \\
\hline abd & $S \mathrm{SS}$ & S & & & & & W & $\mathrm{s}$ & \\
\hline Brown et & B B B & & $3 \mathrm{~B}$ & BB & B & BB & B $\mathrm{B}$ BB & BB & BB BB \\
\hline Reche \& Reinherz [4] & $\mathrm{R} R \mathrm{R}$ & & $R R R$ & $R R$ & & $\mathrm{R} \quad \mathrm{R}$ & $\mathrm{R} \quad \mathrm{R}$ & $\mathrm{R} \quad \mathrm{R}$ & RR $\quad \mathrm{RR}$ \\
\hline
\end{tabular}

Figure 4 Amino acid alignment of $\boldsymbol{\beta}$ 1-domain. MHII $\beta 1$ sequences for $\boldsymbol{H}$. abdominalis (Hiab), Homo sapiens (Hosa) and published teleost species (see methods). "S" represents positively selected sites in the seahorse as inferred from the exon 2 dataset, "B" indicates human PBS according to Brown et al. [10] and "R" reflects human PBS according to Reche and Reinherz [50]. Amino acid positions of the human MHII $\beta 1$ domain are indicated below the human sequence.

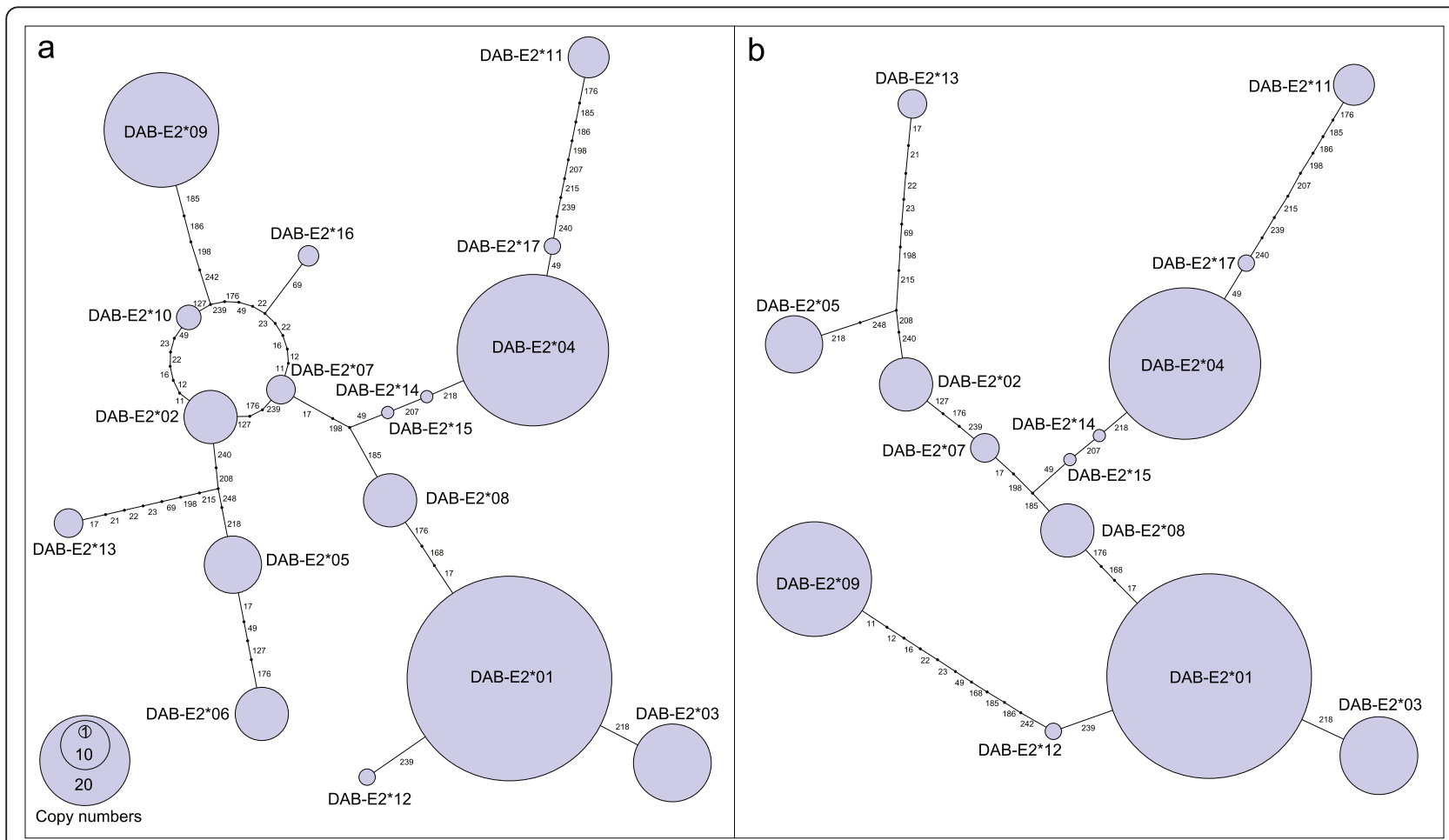

Figure 5 Allele network of exon $\mathbf{2}$. MHII exon 2 nucleotide sequences for $101 \mathrm{H}$. abdominalis individuals. Circle sizes reflect allele frequencies. The positions of individual non-synonymous substitutions separating sequences are indicated. Figure 5a: All 17 alleles. Figure 5b: Recombinant alleles (RECCO: $p<0.05$ ) have been removed (DAB-E2*06, DAB-E2*10 and DAB-E2*16). 
Table 2 Synonymous and non-synonymous substitution rates for exon 2 alleles of the seahorse MHII $\beta$ gene.

\begin{tabular}{llllllll}
\hline Locus & $\begin{array}{l}\text { Length } \\
\text { (bp) }\end{array}$ & Samples & Alleles & $\mathbf{d N}$ & $\mathbf{d S}$ & $\mathbf{d N} / \mathbf{d S}$ \\
\hline Exon 2 & 270 & 101 & 17 & 0.041 & 0.011 & $3.73^{*}$ \\
Exon 2, PBS & 72 & 101 & 15 & 0.128 & 0.009 & $14.22^{* *}$ \\
Exon 2, non- & 198 & 101 & 9 & 0.018 & 0.012 & $1.50^{\text {ns }}$ \\
PBS & & & & & & &
\end{tabular}

Probabilities $\left({ }^{*}<0.05,{ }^{* *}<0.001, \mathrm{~ns}=\right.$ not significant) are derived from a Z-test $(\mathrm{H} 1=$ positive selection). Peptide binding sites (PBS) refer to the human sites, identified by crystallographic analysis in Brown et al. [10].

statistical analyses (RECCO, p $<0.01$ ), which indicate that $3 \mathrm{MHII} \beta$ alleles are the result of intralocus recombination (Hiab-DAB-E2*06: $\mathrm{p}=0.01$, Hiab-DAB-E2*10: $\mathrm{p}=0.01$ and Hiab-DAB-E2*16: p =0.03). A network without these recombinant alleles is qualitatively similar to the full network, but the placement of Hiab-DAB$E 2 * 09$ shifts in the pruned dataset, reflecting its high level of divergence from the central haplotypes (Figure $5 b)$.

\section{Discussion}

The sex-role reversed potbellied seahorse, $H$. abdominalis, has a single MHII $\beta$ gene, which exhibits the typical vertebrate pattern of high genetic diversity. The existence of a maximum of 2 MHII $\beta$ alleles per individual and the analysis of parent-offspring genotypes in 5 families of seahorses supports the Mendelian segregation of a single locus in this species. The high variability of the $\beta 1$-domain of this gene, the region interacting with antigens, has been generated and maintained by a combination of positive selection and intralocus recombination, factors which have been shown to influence the pattern of $\mathrm{MH}$ variation in species with conventional sex roles $[7,26]$. The results of targeted gene sequencing are congruent with a transcriptome screen which indicates that a single copy of this locus is expressed in muscle, liver and brood pouch tissue of the seahorse. The expression of MHII $\beta$ in pouch tissue of $H$. abdominalis males suggests that MH molecules may be immunologically active in brood-pouch tissues, and could possibly play a role in immune protection during the development of embryos in the paternal brood pouch [36].

\section{Genetic diversity}

Previous studies of MHII $\beta$ diversity in teleost fishes have demonstrated the exceptionally high diversity of this locus in this group (reviewed in [7]). These studies have, however, focused on species with conventional sex roles, with female-based mate choice and male-male competition (e.g. Gasterosteus aculeatus [37], Oncorhynchus spp., Perca fluviatilis [38] and Poecilia reticulata [39]).
As males and females often differ in their ability to detect olfactory cues [32,33], the efficiency of odorbased MHC-mediated choice as a selective mechanism might be expected to differ between sex-role reversed and conventionally-mating species. Disassortative mating is thought to act together with pathogen-mediated selection to maintain MHC diversity $[15,20]$, and species which lack the ability to detect and process $\mathrm{MHC}$-based odor cues are thus expected to exhibit reduced levels of $\mathrm{MHC}$ diversity relative to species experiencing both forms of selection. Contrary to this hypothesis, MHII $\beta$ diversity in the sex-role reversed seahorse is similar to that detected in other teleosts (see below), suggesting that sex-role reversed species are capable of maintaining the high $\mathrm{MH}$ diversity typical in other vertebrates. Both natural and sexual selection are thought to influence $\mathrm{MH}$ diversity [8], but the observation of high MHII $\beta$ diversity in a sex-role reversed species suggests that natural selection may be sufficient to generate this high variability, a hypothesis which is currently being investigated using individual-based simulations (Ejsmond MJ, Radwan J and Wilson AB, in prep.). Alternatively, sexrole reversed species may indeed be capable of processing $\mathrm{MH}$-based olfactory cues, something which is currently under investigation in targeted mate choice experiments in the seahorse.

MHII $\beta$ gene-copy variation is high in teleosts, and while some teleost fishes have more than 10 functional copies of MHII $\beta$, a small number of species have only a single locus. Perhaps the best studied example of this are the ancestral tetraploid salmonids, who possess a single classical MHII $\beta$ gene [25]. The high MHII $\beta 1$ domain diversity of the potbellied seahorse is similar to that found in this group. The seahorse carries a similar number of alleles $(H$. abdominalis: 17 alleles in 101 individuals, Oncorhynchus gilae gilae: 5/142, O. tshawytscha: 12/144, Salmo trutta: 24/180, O. mykiss: 88/423), but exhibits fewer polymorphic sites (25 variable sites, $6.2 \%$ polymorphism) than that found in salmonids (21 - 70 variable sites, $7.7-27.2 \%$ polymorphism) [40-43]. $H$. abdominalis and salmonids show comparable nucleotide diversities in the PBR-containing $\beta 1$-domain of exon 2 (H. abdominalis: $\pi=0.034$; O. gilae gilae: $\pi=0.040$ [43]; S. trutta: $\pi=0.054$ [41]).

As interlocus gene conversion is thought to contribute to the diversity of gene families [44], one might expect to see higher intralocus variability in species carrying multiple MHII $\beta$ loci. While species carrying several functional copies of MHII $\beta$ possess a higher total number of alleles, intralocus measures of MHII $\beta$ PBR diversity in these species are in fact less than those observed in species with only a single locus. Three-spined sticklebacks (Gasterosteus aculeatus), an important model system for the study of teleost $\mathrm{MH}$ evolution, are thought 
to carry at least 4 copies of MHII $\beta[16,26,45]$. A recent survey of 48 sticklebacks from locations in Europe and North America detected a total of 31 exon 2 alleles, or $\leq 8$ alleles per locus [26]. Similarly, a survey of Trinidadian guppies, Poecilia reticulata, a species with at least 2 MHII $\beta$ loci, recovered 18 exon 2 alleles in 56 individuals (alleles per locus $\leq 9$ ) [21]. This pattern can also be observed in other species, for example in Poecilia formosa [46] and Perca fluviatilis [27], with 9 alleles in 29 individuals ( $\geq 2$ MHII $\beta$ loci; $\leq 5$ alleles per locus) and 28 alleles in 58 individuals ( $\geq 8$ MHII $\beta$ loci; $\leq 4$ alleles per locus), respectively. Methodological differences in the sample sizes and spatial scales of studies of $\mathrm{MH}$ variation complicate comparative analyses of genetic diversity, but the fact that species carrying a single MHII $\beta$ locus have levels of allelic variation equal or greater than those detected in species with multiple copies of these loci (see above), suggests that intralocus allelic diversity of the MHII $\beta$ PBR does not necessarily increase when more genes are present in a species. It is important to note, that maximal MHC diversity may also be constrained, both by interactions with the autoimmune response $[47,48]$ and by consistently high levels of interlocus gene conversion, which may tend to homogenize genetic variation in species carrying multiple copies of these genes [49]. These factors may, in part, explain the lower than expected levels of $\mathrm{MH}$ variation detected in such species relative to species carrying a single copy of these genes.

\section{Peptide binding sites}

We detected an excess of non-synonymous substitutions relative to synonymous substitutions in the PBR-encoding $\beta 1$-domain of the seahorse, a pattern consistent with that found in species with conventional female-based mate choice. Due to the lack of X-ray crystallographic structure analyses of teleost MH genes, PBS in fishes are typically inferred by homology modeling to human MHC loci [50]. In addition, sites exhibiting a high variability and signatures of positive selection are also putative candidates for peptide binding sites [8,51,52]. 17 of the 90 MHII $\beta 1$-domain sites of the seahorse are variable (19\%), and 11 of these variable sites (65\%) show evidence of positive selection. 9 of 11 sites correspond to human PBS as inferred by Reche and Reinherz [50] (Figure 4). While the length of the MHII $\beta 1$-domain sequenced often differs between studies, several recent studies have analysed site-specific variation in the same 56 amino acid fragment of MHII $\beta 1$, stretching from position 25 to 80 of the human alignment (Figure 4). A comparison among these studies indicates that the proportion of sites under positive selection in this region is similar between the sex-role reversed seahorse $(6 / 56=$ $11 \%)$, and conventionally mating salmonids (5-21\%,
[40]), Poecilia spp. (11-15\%, [46]) and perch (22\%, [27]), illustrating the striking consistency in the pattern of $\mathrm{MH}$ variation among species, despite differences in their sex roles.

\section{Conclusions}

We provide the first data on the pattern of $\mathrm{MH}$ diversity in the seahorse ( $H$. abdominalis), a species with an exceptionally well-developed form of paternal care and male mate choice. The sex-role reversed $H$. abdominalis exhibits levels of MHII $\beta$ diversity similar to that detected in species with conventional sex roles. This species has a single functional $\mathrm{MH}$ class II beta-chain gene that is expressed in the male brood pouch, suggesting that this gene may be immunologically active in these tissues. The pattern of MHII $\beta$ genetic diversity in the seahorse has been influenced by positive selection and recombination, and intralocus genetic diversity in this species exceeds that present in species carrying multiple copies of this gene. Mating experiments are currently being used to determine whether $\mathrm{MH}$-odor cues are used in mate choice decisions in $H$. abdominalis, data which should help to shed light on the relative roles of natural and sexual selection in generating the high levels of MHII $\beta$ diversity found in the seahorse.

\section{Methods}

\section{Full-length MHII $\beta$ gene sequencing}

Whole genomic DNA was extracted from muscle tissue of a single $H$. abdominalis individual using a standard proteinase $\mathrm{K} /$ phenol-chloroform protocol [53]. To characterize MHII $\beta$ genes in the seahorse, we first designed primers in conserved regions of the gene. These regions were identified using an alignment of published sequences for 11 teleost species (Danio rerio - Dare [GenBank:AAA50043], Salmo salar - Sasa [GenBank: AJ439067], Cyprinus carpio - Cyca [GenBank: CAD89312, CAA64709], Tetraodon nigroviridis - Teni [GenBank:CAF94187], Oryzias latipes - Orla [GenBank: BAA94279, BAA94280], Poecilia reticulata - Pore [GenBank:Z54077], Stizostedion vitreum - Stvi [GenBank: AY158837], Paralichthys olivaceus - Paol [GenBank: AB126922, AB126923, AY848955], Gasterosteus aculeatus - Gaac [GenBank:AY713945], Hippocampus kuda Hiku [GenBank:AY211533], Takifugu rubripes - Taru [Ensembl:ENSTRUP00000004737], Oryzias latipes - Orla [Ensembl:ENSORLG00000000025]). Sequences were aligned in BioEdit v.7.0.9.1 [54] and primers were designed using Primer3 v.0.4.0 [55]. Primers used for MHII $\beta$ sequencing are provided in Table 3 and their locations on the seahorse MHII $\beta$ gene are indicated in Figure 1.

To amplify MHII $\beta$, we used long-range PCR under the following conditions: $1 \times$ ThermoPol reaction buffer 
Table 3 Primers used to amplify and sequence MHII $\beta$ in H. abdominalis.

\begin{tabular}{lll}
\hline Name & Sequence 5'-3' $^{\prime}$ & Location \\
\hline MHIIIb-E1F2 & GCCTCCTITCCTCACCTTC & Exon 1 \\
MHIIIb-I1F & TTGCGACTACACATTCAGCA & Intron 1 \\
MHIIIb-I2F2 & TIIIIITATCCCTTAACACTTAGAATACAG & Intron 2 \\
MHIIIb-I2F3 & CGGGTCAACGAGTTCTCAAC & Intron 2 \\
MHIIIb-I2R & ACCAATGATTGTCGGGTGT & Intron 2 \\
MHIIIb-I2R2 & TCGGGTGTGATAATGGTCTG & Intron 2 \\
MHIIIb-I2R4 & GGCGGCTGATTATCATGTTT & Intron 2 \\
MHIIIb-I2R5 & TTGCGCCAAGGACCGGTTAATG & Intron 2 \\
MHIIIb-E3F & GACGGCGACTGGTACTATCA & Exon 3 \\
MHIIIb-E3R & TGATAGTACCAGTCGCCGTC & Exon 3 \\
MHIIIb-E3R2 & TCTGCTTGGGGTAGAAGTCG & Exon 3 \\
MHIIIb-E4R & AAGGCTGGCGTGTTCCAC & Exon 4 \\
MHIIIb-I4F & CGGGGGTCTTAAATCCTGTT & Intron 4 \\
MHIIIb-E5F & CTITCCCTGGGAGGCTTC & Exon 5 \\
MHIIIb-E6R & TGGGAACCAGAATGCGACC & Exon 6 \\
\hline
\end{tabular}

(NEB), $1.2 \mu \mathrm{M}$ dNTPs, $0.9 \mu \mathrm{M}$ of each primer, $1.5 \mathrm{U}$ of a 1:20 Pfu DNA polymerase (Promega) and Taq DNA Polymerase (NEB) mixture and approx. 60 ng DNA per $30 \mu \mathrm{L}$ reaction. PCR running conditions involved an initial denaturation at $92^{\circ} \mathrm{C}$ for $5 \mathrm{~min}$, followed by 35 cycles of $92^{\circ} \mathrm{C}$ for $30 \mathrm{sec}, 58^{\circ} \mathrm{C}$ for $30 \mathrm{sec}$ and $68^{\circ} \mathrm{C}$ for $0.5-4$ min (depending on product length), with a final extension at $68^{\circ} \mathrm{C}$ for $5-15 \mathrm{~min}$.

As the initial primer set provided only a fragment of the MHII $\beta$ locus, genome walking was used to complete the sequence using a protocol modified from the Universal GenomeWalker Kit (Clontech). One $\mu$ g of highquality genomic DNA was digested separately with $10 \mathrm{U}$ of the enzymes EcoRV (NEB), PvuII (NEB), StuI (NEB), DraI (NEB), AluI (Promega), HincII (NEB) and Cac8I (NEB) according to the manufacturer's recommendations. Purification of digested DNA and adaptor ligation followed the Clontech protocol. Genome walking was performed using a nested PCR approach with $1 \times$ ThermoPol reaction buffer, $1 \mu \mathrm{M}$ dNTPs, $0.4 \mu \mathrm{M}$ AP1 primer, $0.4 \mu \mathrm{M}$ gene-specific primer 1, $1 \mathrm{U}$ Taq DNA polymerase (NEB) and $1 \mu \mathrm{L}$ of the DNA-adaptor-library in a $20 \mu \mathrm{L}$ reaction volume for the first round PCR. The nested PCR was performed using the same protocol, but with the AP2 primer and a nested gene-specific primer along with $1 \mu \mathrm{L}$ of a 1:50 dilution of the initial PCR product. Cycling conditions were identical in both PCRs, with $2 \mathrm{~min}$ at $92^{\circ} \mathrm{C}, 30$ cycles of $30 \mathrm{sec}$ at $92^{\circ} \mathrm{C}, 30 \mathrm{sec}$ at $57^{\circ} / 60^{\circ} / 63^{\circ} \mathrm{C}$ and $3 \mathrm{~min}$ at $68^{\circ} \mathrm{C}$.

PCR products were purified for sequencing using either a MultiScreen PCR filter plate (Millipore), gelpurification with the Wizard SV Gel and PCR Clean-Up System (Promega), or via cloning with a Topo TA Cloning Kit (Invitrogen) following the manufacturers' recommendations. 10-20 positive colonies per plate were picked into $25 \mu \mathrm{L}$ of ddH20, directly PCR-amplified and sequenced. Cloned products were compared to direct sequences generated with several different primer combinations, in order to identify allelic phase and to identify any cloning-mediated PCR artifacts. Purified PCR products were prepared for sequencing by adding 1 $\mu \mathrm{L}$ Big Dye v3.1 Terminator Cycle Sequencing mixture (Applied Biosystems) and $1 \mu \mathrm{L}$ primer to $2-8 \mu \mathrm{l}$ of purified product in a $10 \mu \mathrm{L}$ volume. Cycling conditions were 30 cycles of $10 \mathrm{sec}$ at $96^{\circ} \mathrm{C}, 5 \mathrm{sec}$ at $50^{\circ} \mathrm{C}$ and $4 \mathrm{~min}$ at $60^{\circ} \mathrm{C}$. Ethanol-purified products were sequenced on an ABI 3730 automated sequencer (Applied Biosystems).

\section{Analysis of gene expression and MHII $\beta$ copy number}

To determine whether MHII $\beta$ sequences obtained from genomic DNA represent functional alleles, we amplified and sequenced a partial MHII $\beta$ cDNA sequence (exon 2 -5) from liver, muscle and pouch tissue of a reproductively mature non-pregnant male seahorse. RNA was extracted using TRIZOL ${ }^{\circledR}$ Reagent (Invitrogen) according to the manufacturers' recommendations. One $\mu \mathrm{g}$ of purified RNA was digested with $9 \mu \mathrm{L}$ of DNase I (Promega) and reverse-transcribed into cDNA with $1 \mu \mathrm{L}$ ImProm II Reverse Transcriptase (Promega) using $2 \mu \mathrm{L}$ of a $500 \mu \mathrm{g} / \mu \mathrm{L}$ solution of a dT-adaptor primer (TAGGAATTCTCGAGCGGCCGCTTTTTTTTTTTT) in 25 $\mu \mathrm{L}$ volume. The program for the RT-PCR followed the manufacturer's recommendations (Promega). $3 \mu \mathrm{L}$ of a 1:2 dilution of Millipore-purified cDNA was used as template in a PCR reaction with MHIIb-E1F2 and MHIIb-E6R under the standard PCR conditions outlined above.

Genomic DNA and cDNA sequencing indicate that $H$. abdominalis possesses a single functional MHII $\beta$ gene (see below). To further explore this pattern, we screened cDNA libraries of seahorse pouch and reference tissues from pregnant and non-pregnant individuals for the presence of MH genes using 454 sequencing. Briefly, both normalized and unnormalized cDNA libraries prepared from purified total RNA derived from the pouch tissues of a single pregnant and non-pregnant seahorse, together with a pool of normalized reference tissues from the pregnant individual (brain, gills, liver, heart, kidney and testes), were individually MID-tagged with a unique sequence identifier. MID-tagged libraries were sequenced using GS FLX Titanium Chemistry (Roche), following the manufacturer's recommendations. A full plate of 454 sequencing yielded a total of $850 \mathrm{~K}$ filtered reads (average read length $230 \mathrm{bp}$ ), 92\% of which could be assembled into $38 \mathrm{~K}$ contigs. The full results of this transcriptome screen will be described in detail elsewhere (Gauthier MEA, Stölting KN and Wilson AB, in prep.). 


\section{Characterization of the MHII $\beta$ peptide binding region (PBR)}

In order to investigate the hypervariable PBR of MHII $\beta$, complete exon 2 sequences were amplified in an additional 100 individuals as part of a larger study investigating MH-based mate choice preferences in the seahorse. Seahorses are listed under Appendix II of the United Nations Convention on the International Trade in Endangered Species (CITES), and the majority of the samples included here thus originate from a captivebred population derived from individuals collected from several sex-role reversed Tasmanian populations. The seahorses in this captive-bred population are held in large communal breeding tanks $(2,100 \mathrm{~L})$ with 50 males and 50 females per tank, allowing free mate choice (Hawkins R, pers. comm.). This population is genetically diverse (20 - 29 alleles per microsatellite locus; $\mathrm{n}=4$ loci) and an individual-based assignment test indicates the existence of a single Tasmanian population of captive-bred and wild-caught individuals (Structure: $\operatorname{Pr}(\mathrm{K}=$ 1) $=1$; see Additional file 1). A global test of microsatellite data failed to reject the null-hypothesis of HardyWeinberg equilibrium in this population (HWE Exact Test: $p=0.21$ ). In addition to 95 individuals from the captive-bred population, we obtained complete exon 2 sequences from 5 wild-caught seahorses from Sydney, Australia (2 individuals collected in 2003) and Tasmania (3 individuals collected from 3 populations in 2003 and 2004). Genomic DNA from these individuals was extracted from fin clips using a DNeasy 96 Tissue Kit (QIAGEN). PCR products for exon 2 were generated using either primer MHIIb-E1F2 or MHIIb-I1F together with primer MHIIb-I2R4 (see PCR conditions above) and directly sequenced. Sequencing results were identical using either primer combination (data not shown). All private haplotypes were sequenced in a minimum of 2 independent runs in order to reduce the possibility of PCR artifacts. Degenerate positions in heterozygote sequences were scored using IUPAC nomenclature to facilitate the inference of allelic phase (see below).

\section{MHII $\beta$ inheritance}

We obtained exon 2 sequences from $47 \mathrm{~F} 1$ individuals from 5 families ( $\mathrm{n}=8-13$ per family), to investigate whether $\mathrm{MH}$ alleles segregate in a Mendelian fashion. This approach demonstrates the mode of inheritance of these loci and provides a means to evaluate the reliability of sequence profiles generated for this fragment of the MHII $\beta$ gene, through parent-offspring comparisons.

\section{Processing of sequences}

Sequence data were assembled using Sequencing Analysis 5.2 (Applied Biosystems). Sequences were aligned with Muscle v.4.0 [56] and verified by eye in BioEdit v.7.0.9 [54]. To investigate the peptide binding region (PBR), we analysed 270 bp sequences of exon 2 (total length: $273 \mathrm{bp}$ ) after omitting the first 2 nucleotides and the final nucleotide of exon 2 , to obtain a complete reading frame. As all exon 2 alleles are derived from a single MHII $\beta$ locus (see below), they are named Hiab$D A B-E 2 * 01-17$, following standard terminology [57]. $\mathrm{MH}$ haplotypes of each individual were inferred from degenerate sequence data using a Bayesian statistical method implemented in PHASE v.2.1 using the default parameters [58], an approach which allows the determination of allelic phase from degenerate electrophoretic profiles [59]. SeqPHASE was used to convert between the PHASE input/output file and the sequence alignment [60].

\section{Analyses of sequence polymorphism}

DnaSP v.4.90.1 [61] was used to calculate standard estimates of genetic diversity. To visualize relationships among the different exon 2 alleles and the non-synonymous substitutions separating them, a haplotype network was prepared using TCS v.1.21 [62]. The conversion of the sequence alignment file into a TCSfile was done with FaBox v.1.35 [63] and the final network was prepared using yED v.3.2.0.1 [64]. Tests for Hardy Weinberg equilibrium were performed in Genepop on the web $[65,66]$ using the default settings for the Markov Chain search. The analysis of non-random associations of alleles was performed using non-parametric simulations (10,000 permutations), incorporating empirical allele frequencies, with the Monte Carlo simulation function in PopTools v.3.0.6 [67]. 95\% confidence intervals of simulated data provided an estimate of expected frequencies of allelic combinations.

\section{Positive selection}

$\mathrm{dN}$ and $\mathrm{dS}$ were calculated using Mega v.4.0.2 [68] under a Jukes-Cantor model. Mega v.4.0.2 [68] was also used to test for positive selection in the dataset, applying a Z-test under a Jukes-Cantor model (10,000 permutations). Site-specific positive selection was inferred using Codeml, implemented in the PAML v.4.2b package [69]. Codeml tests the goodness of fit of codon substitution models to a dataset using maximum likelihood. A neighbor-joining tree was generated for the 17 exon 2 alleles using Neighbor v.3.5c [70] under default settings, as implemented in BioEdit v.7.0.9. We compared the fit of a neutral evolution model with recombination (M7) with one allowing for positive selection (M8), using a likelihood-ratio test (LRT). Most previous studies on patterns of variation at vertebrate MHC loci have used the original human crystallographic structure of MHCII $\beta$ prepared by Brown et al. [10] to infer putative peptide binding sites. More recently, Reche and 
Reinherz [50] presented an updated model of human PBS based on a larger sampling of potential peptides. In order to facilitate comparisons with previous studies, codons of the seahorse PBR were inferred through homology modeling to both of these datasets (see Figure 4). Given the more comprehensive dataset included in the Reche and Reinherz paper [50], PBS inferences in future studies should place greater emphasis on this work.

\section{Recombination}

Recombination in the seahorse exon 2 dataset was tested using the default settings of RECCO v.0.93 (10,000 permutations) [71]. The identification of recombinant alleles with RECCO is based on a minimal cost solution, in which the relative cost of obtaining a sequence in an alignment from the other sequences by mutation and recombination is evaluated.

\section{Additional material}

Additional file 1: Figure S1: Genetic structure plot.

\section{Acknowledgements}

We thank L. Keller and C. Wedekind for helpful discussions during the preparation of this manuscript. We are grateful to K.N. Stölting for his suggestions for lab work and data analyses as well as for providing preliminary analyses of the 454 data. Funding for this work has been provided by the University of Zurich.

\section{Authors' contributions}

$A B$ participated in the design of the study, carried out the laboratory work and data analysis and wrote the manuscript. ABW conceived the study, supervised the laboratory work and data analysis and helped to draft the manuscript. Both authors read and approved the final manuscript.

Received: 22 November 2010 Accepted: 10 May 2011

Published: 10 May 2011

\section{References}

1. Andersson M: Sexual selection Princeton, New Jersey: Princeton University Press; 1994.

2. Emlen ST, Oring LW: Ecology, sexual selection, and evolution of mating systems. Science 1977, 197:215-223.

3. Andersson M: Evolution of classical polyandry: Three steps to female emancipation. Ethology 2005, 111:1-23.

4. Clutton-Brock TH, Vincent ACJ: Sexual selection and the potential reproductive rates of males and females. Nature 1991, 351:58-60.

5. Eens $M$, Pinxten R: Sex-role reversal in vertebrates: Behavioural and endocrinological accounts. Behavioural Processes 2000, 51:135-147.

6. Milinski M: The major histocompatibility complex, sexual selection, and mate choice. Annu Rev Ecol Evol Syst 2006, 37:159-186.

7. Wegner KM: Historical and contemporary selection of teleost MHC genes: Did we leave the past behind? J Fish Biol 2008, 73:2110-2132.

8. Piertney SB, Oliver MK: The evolutionary ecology of the major histocompatibility complex. Heredity 2006, 96:7-21.

9. Janeway CA, Travers P, Walport M, Shlomchik M: Immunologie Heidelberg, Berlin: Spektrum; 2002

10. Brown JH, Jardetzky TS, Gorga JC, Stern LJ, Urban RG, Strominger JL, Wiley DC: 3-Dimensional structure of the human class-II histocompatibility antigen HLA-DR1. Nature 1993, 364:33-39.
11. Hedrick PW: Balancing selection and MHC. Genetica 1998, 104:207-214.

12. Penn DJ: The scent of genetic compatibility: Sexual selection and the major histocompatibility complex. Ethology 2002, 108:1-21.

13. van Oosterhout $\mathrm{C}$ : A new theory of $\mathrm{MHC}$ evolution: Beyond selection on the immune genes. Proc $R$ Soc Biol 2009, 276:657-665.

14. Shiina T, Ota M, Shimizu S, Katsuyama Y, Hashimoto N, Takasu M, Anzai T, Kulski JK, Kikkawa E, Naruse T, Kimura N, Yanagiya K, Watanabe A, Hosomichi K, Kohara S, Iwamoto C, Umehara Y, Meyer A, Wanner V, Sano K, Macquin C, Ikeo K, Tokunaga K, Gojobori T, Inoko H, Bahram S: Rapid evolution of major histocompatibility complex class I genes in primates generates new disease alleles in humans via hitchhiking diversity. Genetics 2006, 173:1555-1570.

15. Penn DJ, Potts WK: The evolution of mating preferences and major histocompatibility complex genes. Amer Nat 1999, 153:145-164.

16. Reusch TBH, Häberli MA, Aeschlimann PB, Milinski M: Female sticklebacks count alleles in a strategy of sexual selection explaining MHC polymorphism. Nature 2001, 414:300-302.

17. Milinski M: The function of mate choice in sticklebacks: Optimizing MHC genetics. J Fish Biol 2003, 63:1-16.

18. Aeschlimann PB, Haberli MA, Reusch TBH, Boehm T, Milinski M: Female sticklebacks Gasterosteus aculeatus use self-reference to optimize MHC allele number during mate selection. Behav Ecol Sociobiol 2003, 54:119-126.

19. Forsberg LA, Dannewitz J, Petersson E, Grahn M: Influence of genetic dissimilarity in the reproductive success and mate choice of brown trout - females fishing for optimal MHC dissimilarity. J Evol Biol 2007, 20:1859-1869.

20. Spurgin LG, Richardson DS: How pathogens drive genetic diversity: MHC, mechanisms and misunderstandings. Proc R Soc Biol 2010, 277:979-988.

21. van Oosterhout C, Joyce DA, Cummings SM, Blais J, Barson NJ, Ramnarine IW, Mohammed RS, Persad N, Cable J: Balancing selection, random genetic drift, and genetic variation at the major histocompatibility complex in two wild populations of guppies (Poecilia reticulata). Evolution 2006, 60:2562-2574

22. Sato A, Figueroa F, Murray BW, Malaga-Trillo E, Zaleska-Rutczynska Z, Sultmann H, Toyosawa S, Wedekind C, Steck N, Klein J: Nonlinkage of major histocompatibility complex class I and class II loci in bony fishes. Immunogenetics 2000, 51:108-116.

23. Stet RJM, Kruiswijk CP, Dixon B: Major histocompatibility lineages and immune gene function in teleost fishes: The road not taken. Crit Rev Immunol 2003, 23:441-471.

24. Stet RJM, de Vries B, Mudde K, Hermsen T, van Heerwaarden J, Shum BP, Grimholt U: Unique haplotypes of co-segregating major histocompatibility class II A and class II B alleles in Atlantic salmon (Salmo salar) give rise to diverse class II genotypes. Immunogenetics 2002, 54:320-331.

25. Harstad H, Lukacs MF, Bakke HG, Grimholt U: Multiple expressed MHC class II loci in salmonids; details of one non-classical region in Atlantic salmon (Salmo salar). BMC Genomics 2008, 9:193-209.

26. Reusch $\mathrm{TBH}$, Langefors $\mathrm{A}$ : Inter- and intralocus recombination drive $\mathrm{MHC}$ class IIB gene diversification in a teleost, the three-spined stickleback Gasterosteus aculeatus. J Mol Evol 2005, 61:531-541.

27. Michel C, Bernatchez L, Behrmann-Godel J: Diversity and evolution of MHII $\beta$ genes in a non-model percid species - The Eurasian perch (Perca fluviatilis L.). Mol Immunol 2009, 46:3399-3410.

28. Malaga-Trillo E, Zaleska-Rutczynska Z, McAndrew B, Vincek V, Figueroa F Sultmann $\mathrm{H}$, Klein J: Linkage relationships and haplotype polymorphism among cichlid MHC class II B loci. Genetics 1998, 149:1527-1537.

29. Nei M, Rooney AP: Concerted and birth-and-death evolution of multigene families. Annu Rev Genet 2005, 39:121-152.

30. Agbali M, Reichard M, Bryjova A, Bryja J, Smith C: Mate choice for nonadditive genetic benefits correlate with $\mathrm{MHC}$ dissimilarity in the rose bitterling (Rhodeus ocellatus). Evolution 2010, 64:1683-1696.

31. Landry C, Garant D, Duchesne P, Bernatchez L: 'Good genes as heterozygosity': The major histocompatibility complex and mate choice in Atlantic salmon (Salmo salar). Proc R Soc Biol 2001, 268:1279-1285.

32. Hamdani $E H$, Doving KB: The functional organization of the fish olfactory system. Prog Neurobiol 2007, 82:80-86

33. Good KP, Kopala L: Sex differences and olfactory function. In Olfaction and the Brain. Edited by: Brewer WJ, Castle D, Pantelis C. Cambridge UK Cambridge University Press; 2006:183-202. 
34. Wilson $A B$, Ahnesjö I, Vincent $A C J$, Meyer $A$ : The dynamics of male brooding, mating patterns, and sex roles in pipefishes and seahorses (family Syngnathidae). Evolution 2003, 57:1374-1386.

35. Wilson AB, Martin-Smith KM: Genetic monogamy despite social promiscuity in the pot-bellied seahorse (Hippocampus abdominalis). Mol Ecol 2007, 16:2345-2352.

36. Stölting KN, Wilson AB: Male pregnancy in seahorses and pipefish: Beyond the mammalian model. BioEssays 2007, 29:884-896.

37. Bell MA, Foster SA: The Evolutionary Biology of the Threespine Stickleback Oxford, UK: Oxford University Press, USA; 1994.

38. Breder CM, Rosen DE: Modes of Reproduction in Fishes Neptune City, New Jersey: T.F.H. Publications; 1966

39. Houde AE: Sex roles, ornaments, and evolutionary explanation. Proc Nat Acad Sci USA 2001, 98:12857-12859.

40. Aguilar A, Garza JC: Patterns of historical balancing selection on the salmonid major histocompatibility complex class II beta gene. J Mol Evol 2007, 65:34-43

41. Campos UL, Posada D, Moran P: Genetic variation at MHC, mitochondrial and microsatellite loci in isolated populations of Brown trout (Salmo trutta). Conserv Genet 2006, 7:515-530.

42. Neff BD, Garner SR, Heath JW, Heath D: The MHC and non-random mating in a captive population of Chinook salmon. Heredity 2008, 101:175-185.

43. Peters MB, Turner TF: Genetic variation of the major histocompatibility complex (MHC class II beta gene) in the threatened Gila trout, Oncorhynchus gilae gilae. Conserv Genet 2008, 9:257-270.

44. Ohta T: On the pattern of polymorphisms at major histocompatibility complex loci. J Mol Evol 1998, 46:633-638.

45. Sato A, Figueroa F, O'hUigin C: Cloning of major histocompatibility complex (MHC) genes from threespine stickleback, Gasterosteus aculeatus. Mol Mar Biol Biotechnol 1998, 7:221-231.

46. Schaschl H, Tobler M, Plath M, Penn DJ, Schlupp I: Polymorphic MHC loci in an asexual fish, the Amazon molly (Poecilia formosa; Poeciliidae). Mol Ecol 2008, 17:5220-5230.

47. Woelfing B, Traulsen A, Milinski M, Boehm T: Does intra-individual major histocompatibility complex diversity keep a golden mean? Philos Trans $R$ Soc London [Biol] 2009, 364:117-128.

48. Nowak MA, Tarczyhornoch K, Austyn JM: The optimal number of major histocompatibility complex molecules in an individual. Proc Natl Acad Sci USA 1992, 89:10896-10899.

49. Martinsohn JT, Sousa AB, Guethlein LA, Howard JC: The gene conversion hypothesis of MHC evolution: A review. Immunogenetics 1999, 50:168-200.

50. Reche PA, Reinherz EL: Sequence variability analysis of human class I and class II MHC molecules: Functional and structural correlates of amino acid polymorphisms. J Mol Biol 2003, 331:623-641

51. Hedrick PW, Whittam TS, Parham P: Heterozygosity at individual amino acid sites - Extremely high levels for HLA-A and HLA-B genes. Proc Natl Acad Sci USA 1991, 88:5897-5901.

52. Schaschl $\mathrm{H}$, Wegner KM: Polymorphism and signature of selection in the MHC class I genes of the three-spined stickleback Gasterosteus aculeatus. J Fish Biol 2006, 69:177-188.

53. Bruford MW, Hanotte O, Brookfield JFY, Burke T: In Molecular Analysis of Populations: A Practical Approach. Edited by: Hoelzel AR. Oxford: IRL Press; 1998:287-336.

54. Hall TA: BioEdit: a user-friendly biological sequence alignment editor and analysis program for Windows 95/98/NT. Nucleic Acids Symp Ser 1999, 41:95-98.

55. Rozen S, Skaletsky HJ: Primer3 on the WWW for general users and for biologist programmers. In Bioinformatics methods and protocols: Methods in molecular biology. Edited by: Krawetz S, Misener S. Totowa, NJ: Humana Press; 2000:365-386.

56. Edgar RC: MUSCLE: Multiple sequence alignment with high accuracy and high throughput. Nucl Acids Res 2004, 32:1792-1797.

57. Ellis SA, Bontrop RE, Antczak DF, Ballingall K, Davies CJ, Kaufman J, Kennedy LJ, Robinson J, Smith DM, Stear MJ, Stet RJM, Waller MJ, Walter L, Marsh SGE: ISAG/IUIS-VIC Comparative MHC Nomenclature Committee report, 2005. Immunogenetics 2006, 57:953-958.

58. Stephens M, Donnelly P: A comparison of Bayesian methods for haplotype reconstruction from population genotype data. Am J Hum Genet 2003, 73:1162-1169.
59. Harrigan RJ, Mazza ME, Sorenson MD: Computation vs. cloning: Evaluation of two methods for haplotype determination. Mol Ecol Resour 2008, 8:1239-1248.

60. Flot JF: SEQPHASE: A web tool for interconverting phase input/output files and fasta sequence alignments. Mol Ecol Resour 2010, 10:162-166.

61. Librado P, Rozas J: DnaSP v5: A software for comprehensive analysis of DNA polymorphism data. Bioinformatics 2009, 25:1451-1452

62. Clement M, Posada D, Crandall KA: TCS: A computer program to estimate gene genealogies. Mol Ecol 2000, 9:1657-1659.

63. Villesen P: FaBox: An online toolbox for FASTA sequences. Mol Ecol Notes 2007, 7:965-968.

64. yWorks: yED Graph Editor v3.2. yWorks, Tübingen, Germany; 2009.

65. Genepop on the Web. [http://genepop.curtin.edu.au/].

66. Raymond M, Rousset F: Genepop (version 1.2) - Population genetics software for exact tests and ecumenicism. J Hered 1995, 86:248-249.

67. PopTools version 3.0.6. [http://www.cse.csiro.au/poptools].

68. Tamura K, Dudley J, Nei M, Kumar S: MEGA4: Molecular evolutionary genetics analysis (MEGA) software version 4.0. Mol Biol Evol 2007, 24:1596-1599.

69. Yang ZH: PAML 4: Phylogenetic analysis by maximum likelihood. Mol Biol Evol 2007, 24:1586-1591.

70. Felsenstein J: PHYLIP (phylogeny inference package) version $3.5 \mathrm{C}$ Distributed by the author Department of Genetics, University of Washington, Seattle; 1993.

71. Maydt J, Lengauer T: Recco: Recombination analysis using cost optimization. Bioinformatics 2006, 22:1064-1071.

doi:10.1186/1471-2148-11-121

Cite this article as: Bahr and Wilson: The impact of sex-role reversal on the diversity of the major histocompatibility complex: Insights from the seahorse (Hippocampus abdominalis). BMC Evolutionary Biology 2011 $11: 121$

\section{Submit your next manuscript to BioMed Central and take full advantage of:}

- Convenient online submission

- Thorough peer review

- No space constraints or color figure charges

- Immediate publication on acceptance

- Inclusion in PubMed, CAS, Scopus and Google Scholar

- Research which is freely available for redistribution

Submit your manuscript at www.biomedcentral.com/submit
C) Biomed Central 